\title{
Pulmonary embolism complicated by ischemic stroke
}

\section{Snezana Lazic*, Bratislav Lazic, Maja Sipic}

Faculty of Medical Science University of Priština, Kosovo
KEYWORDS: pulmonary embolism, ischemic stroke, thrombosis.

CITATION: Cardiol Croat. 2016;11(10-11):528. | DOI: http://dx.doi.org/10.15836/ccar2016.528

*ADDRESS FOR CORRESPONDENCE: Snezana Lazic, Faculty of Medical Science University of Priština, Anri Dinan bb, Kosovska Mitrovica 38220, Kosovo. / Phone: +381-666060569 / E-mail: snezana_lazic@yahoo.com

ORCID: Snezana Lazic, http://orcid.org/0000-0001-6362-3713 • Bratislav Lazic, http://orcid.org/0000-0002-1186-140X Maja Sipic, http://orcid.org/0000-0003-4173-1224

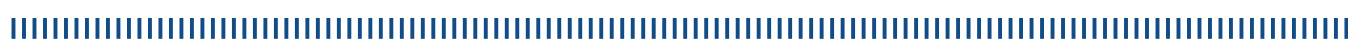

Introduction: After surviving a stroke, paralysis of limbs is often encountered followed by deep vein thrombosis and the possible development of pulmonary embolism. However, pulmonary embolism can become complicated by a stroke. ${ }^{1,2}$ Aim: To indicate the complexity and interdependence of thrombogenesis.

Case report: Female patient, aged 74 was hospitalized due to labored breathing and fatigue that had started 4 days prior. She has been treated for arterial hypertension and permanent atrial fibrillation; is a smoker and overweight. Upon arrival she is conscious, oriented, dyspneic, afebrile, with normal cardiac and pulmonary exam findings, with no edema or organomegaly present. On the second day of hospitalization sudden hypotension $\left(70 / \mathrm{mmHg}\right.$ ) and hypersaturation $\left(\mathrm{SO}_{2} 60 \%\right.$ ) occurs, ECG shows signs of acute right heart overload (S103T3). Alteplase was administered according to protocol for pulmonary embolism. MSCT pulmonary angiography: complete thrombosis of the right pulmonary artery and its branches and thrombosis of lower branches of the left pulmonary artery. Lung parenchyma accompanied by nonuniformal aeration with wedge-shaped formations and a base towards the costal pleura. Two hours after the administration of fibrinolytics, right-sided hemiplegia develops in patient. Brain CT scan shows acute massive ischemic lesion of the left brain hemisphere (territory of left MCA), along with cerebral edema. Ventricular system and subarachnoid space contain no pathological entities. On the tenth day of admission death occurred.

Conclusion: Ischemic stroke most likely caused by the cumulative impact of systemic hypotension, embolism due to atrial fibrillation as well as systemic hypoperfusion which is the result of decreased stroke volume due to pulmonary embolism. Hypoxemia contributed to hypoperfusion. Due to the global reduction of blood flow the middle cerebral artery was affected.
RECEIVED:

September 19, 2016

ACCEPTED:

October 10, 2016

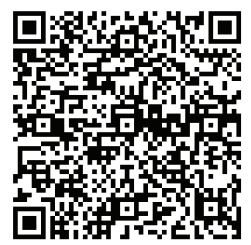

LITERATURE IIIIIIIIIIIIIIIIIIIIIIIIIIIIIIIIIIIIIIIIIIIIIIIIIIIIIIIIIIIIIIIIIIIIIIIIIIIIIIIIIIIIIIIIIIIIIIIIIIIIIIII

1. Bastianetto P, Pinto DM. Pulmonary embolism and stroke associated with mechanical thrombectomy. J Vasc Bras. 2014 Abr.-Jun;13(2):137-141. DOI: http://dx.doi.org/10.1590/jvb.2014.059

2. Savić D, Savić Lj. Prevencija venskog tromboembolizma kod pacijenata sa moždanim udarom. Med Pregl. 2010;63(3-4):220-226. DOI: $h$ ttp://dx.doi.org/10.2298/MPNS1004220S 